\title{
Prevalence of Hyponatremia in Elderly Patients Admitted with Fracture Neck of Femur
}

\author{
${ }^{*}$ Dr. Robin ${ }^{1}$, Dr. Manjunath ${ }^{2}$, Dr. Roshan ${ }^{3}$ \\ ${ }^{I}$ PG Resident, Department of General Medicine, Father Muller Medical College, Mangalore \\ ${ }^{2}$ Associate Professor, Department of Nephrology, Father Muller Medical College, Mangalore \\ ${ }^{3}$ Professor, Department of General Medicine, Father Muller Medical College, Mangalore \\ Corresponding author: * Dr. Robin
}

\begin{abstract}
The aim of the study was to find the prevalence of hyponatremia in elderly patients admitted with femoral neck fracture. This was retrospective study of patients admitted with femoral neck fracture during YEAR 2016. The data was retrieved from hospital data base. The were 90 cases with femoral neck fracture and 400 controls ( group 1 of 200 control population > 18 years, group 2 of 200 contol population > 50 years). Serum sodium was lower in cases than in both the control group (133.2 vs 139.1, 133.2 vs 138.7, P<0.001). The prevalence of hyponatremia was also higher in cases as compared to control group $(58.8 \%$ vs $14 \%, 58.8 \%$ vs $18.5 \%, p<0.001$ ). The odds ratio of hyponatremia for femoral fracture was 6.3 in those who were $>18$ years of age and 8.8 In those who were >50 years of age. Hence it was found that hyponatremia was significantly associated femoral neck fracturein elderly population.
\end{abstract}

Keywords: Hyponatremia, Fracture neck of femur, Elderly, Gait.

\section{Introduction}

Fracture neck of femur as a consequence of fall is a major cause of morbidity and mortality in the elderly population. Single and repeated falls are a special health concern in the elderly. It carries a mortality risk of $13.5 \%$ at 6 months. ${ }^{(1,2)}$ The etiology of fall resulting in fracture neck of femur is multifactorial. Gait instability has been identified as one of the major risk factor. Hyponatremia is a frequent disorder in the elderly, affecting up to $10 \%$ of hospitalized patients. ${ }^{(3)}$ Hyponatremia, generally defined as a serum sodium concentration $<135 \mathrm{mmol} / \mathrm{L}$, has been associated with gait disturbances, falls, and fractures in the elderly. The purpose of this study was to investigate the prevalence of hyponatremia in femoral neck fracture patients admitted to our hospital.

\section{Results}

Elderly population was defined as age above 50 years. There were 90 cases of femoral neck fracture. The control group 1 was age $>18$ years and control group 2 was age $>50$ years. The control group was patients who presented to the hospital for routine health evaluation. Table 1 shows the demographic data of cases and controls.

Table1. demographic data of cases and control population

\begin{tabular}{|c|c|c|c|}
\hline & Cases & Control(group 1) & $P$ value \\
\hline Number & 90 & 200 & \\
\hline $\begin{array}{ll}\text { Average } & \text { serum } \\
\text { sodium(Meg/L) } & \end{array}$ & 133.24 & 139.13 & $<0.001$ \\
\hline Mean age (years) & 72.16 & 58.04 & $<0.001$ \\
\hline Male/female & & \multirow[b]{2}{*}{$28(14)$} & \\
\hline $\begin{array}{l}\text { Number of people with } \\
\text { hyponatremia }(\%)\end{array}$ & $53(58.8)$ & & $<0.001$ \\
\hline Mild(130-135)hyponatremia & 34 & 26 & $<0.001$ \\
\hline $\begin{array}{l}\text { Moderate } \\
\text { 129)hyponatremia }\end{array}$ & 14 & 2 & \\
\hline \multirow[t]{2}{*}{ Severe $(<125)$ hyponatremia } & 5 & 0 & \\
\hline & Cases & Control(group 2) & $P$ value \\
\hline Number & 90 & 200 & \\
\hline $\begin{array}{ll}\begin{array}{l}\text { Average } \\
\text { sodium }(\mathrm{Meq} / \mathrm{L})\end{array} & \text { serum }\end{array}$ & 133.24 & 138.75 & $<0.001$ \\
\hline Mean age (years) & 72.16 & 64.62 & $<0.001$ \\
\hline \multicolumn{4}{|l|}{ Male/female } \\
\hline $\begin{array}{l}\text { Number of people with } \\
\text { hyponatremia }(\%)\end{array}$ & $53(58.8)$ & $37(18.5)$ & $<0.001$ \\
\hline
\end{tabular}




\begin{tabular}{|l|l|l|l|}
\hline Mild(130-135)hyponatremia & 34 & 34 & $<0.001$ \\
\hline $\begin{array}{l}\text { Moderate (125- } \\
\text { 129)hyponatremia }\end{array}$ & 14 & 3 & \\
\hline Severe (<125)hyponatremia & 5 & 0 & \\
\hline
\end{tabular}

Mean serum sodium levels in cases were significantly lower in cases as compared to both the control groups. The prevalence of mild, moderate and severe hyponotremia was also higher and statistically significant in the cases as compared to controls. There was no statistically significant difference in mean sodium levels of both control groups. The odds ratio of hyponatremia for femoral fracture was $6.3(95 \%$ CI 3.63-10.94; $<<0.001$ ) in those who were $>18$ years of age and $8.895 \% \mathrm{CI} 4.92-15.71 ; \mathrm{p}, 0.001$ )in those who were $>50$ years of age. In ROC curve analysis, hyponatremia exhibited a highly significant area under the curve (AUC) for predicting femur fracture $(0.8 ; 95 \% \mathrm{CI}, 0.75$ to $0.85 ; P<0.001)$.

\section{Discussion}

Recently many studies especially from western world have found hyponatremia is associated with fall and fractures especially in elderly. One study found that in elderly patients with femur neck fracture, the prevalence of hyponatremia was found to be more than 3-fold higher compared to patients admitted for elective hip or knee prosthesis. ${ }^{(4)}$ Even mild degree of hyponatremia can cause subtle changes in gait. Hyponatremia affects cognitive function, which can result in unstable walking, causing fall and fractures. ${ }^{(5)}$ Recently chronic hyponatremia is also incriminated as a cause of osteoporosis. ${ }^{(6)}$ Some studies have concluded that identification and management of hyponatremia should be an integral part of fall prevention program. To prevent further episodes of fall, correction of hyponatremia before discharge from hospital is mandatory. ${ }^{(7,8)}$

All the above discussion is of data on western patients. There are no studies looking into the association of hyponatremia and fall in elderly in this part of the country. We found that hyponatremia was significantly associated with femoral fracture in elderly patients. Odds ratio for femoral fracture was 6.3 when compared with general population.

\section{Conclusions}

The fall and femoral neck fracture in elderly is a major cause of morbidity. Many factors are associated with fracture and falls. We found that there is significant association of fracture neck of femur with hyponatremia. Further evaluation is required to find out whether the association is causal or an epiphenomenon. Till further data is available it would be advisable to treat hyponatremia in elderly even if it is asymptomatic.

\section{References}

[1]. Carriero FP, Christmas C. In the clinic. Hip fracture. Ann Intern Med 2011; 155:ITC6-1-ITC6-15.

[2]. Hannan EL, Magaziner J, Wang JJ, Eastwood EA, Silberzweig SB, Gilbert M et.al. Mortality and locomotion 6 months after hospitalization for hip fracture: risk factors and risk-adjusted hospital outcomes. Jama 2001; 285:2736-42.

[3]. Miller M. Hyponatremia and arginine vasopressin dysregulation: mechanisms, clinical consequences, and management. J Am GeriatrSoc. 2006; 54:345-53.

[4]. Tolouian R, Alhamad T, Farazmand M, Mulla ZD. The correlation of hip fracture and hyponatremia in the elderly. J Nephrol. 201 1; 25:789-93.

[5]. Renneboog B, Musch W, Vandemergel X, Manto MU, Decaux G. Mild chronic hyponatremia is associated with falls, unsteadiness, and attention deficits. Am J Med. 2006;119:71 .e1-8

[6]. Verbalis JG, Barsony J, Sugimura Y, Tian Y, Adams DJ. et al. Hyponatremia-induced osteoporosis. J Bone Miner Res. 2010;25:554-63 Cervellin G, Mitaritonno M, Pedrazzoni M, Picanza A, Lippi G. Prevalence of hyponatremia in femur neck fractures: a one-year survey in an urban emergency department. AdvOrthop. 2014;2014:397059.

[7]. Rittenhouse KJ, To T, Rogers A, Wu D, Horst M, Edavettal M, Miller JA, Rogers FB. Hyponatremia as a fall predictor in a geriatric trauma population. Injury. 2015;46:119-23.

[8]. Cumming K, Hoyle GE, Hutchison JD, Soiza RL. Prevalence, incidence and etiology of hyponatremia in elderly patients with fragility fractures. PLoS One. 2014;9:e88272.

*Dr. Robin. "Prevalence of Hyponatremia in Elderly Patients Admitted with Fracture Neck of Femur." IOSR Journal of Dental and Medical Sciences (IOSR-JDMS) 16.7 (2017): 107-108. 